A AUTORA

Solange Puntel Mostafa

Universidade do Vale do Itajaí -

UNIVALI, Santa Catarina.

E-mail: solange@cehcom.univali.br

\title{
CITAÇÕES EPISTEMOLÓGICAS NO CAMPO DA EDUCOMUNICAÇÃO ${ }^{1}$
}

Pesquisa bibliométrica aponta autores nacionais e internacionais mais citados na constituição do campo da comunicação/educação

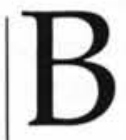

ibliometria é uma área de estudos quantitativos da informação, inaugurada com o surgimento da Ciência da Informação, na década de 60. É tida por alguns como a base intelectual da Ciência da Informação ${ }^{2}$. Isto porque, conforme nos elucida Persson, a ciência pode ser vista como uma rede cognitiva. Os nós da rede são cientistas e seus escritos. Os nós podem ser relacionados de várias maneiras para mapear áreas do conhecimento. Esse mapeamento é feito através

- da análise da produtividade de autores: quais autores são mais produtivos em determinada área?, quais autores fazem parte do núcleo de uma disciplina?;
- da análise da produtividade da área de conhecimento: por que determinadas áreas do conhecimento usam canais de transferência de informação específicos?; isso se constitui num padrão de comportamento?; as literaturas de áreas específicas do conhecimento obedecem a algum padrão em termos de uso?; qual é o índice de obsolescência das áreas?; depois de quanto tempo podemos dizer que a literatura de determinada área envelhece?; há formas de verificar isso?; isso se constitui em especificidade dessa área? como se comporta a literatura de outras áreas?

A Bibliometria interessa aos gestores dos sistemas de informação, às agências financiadoras de pesquisa científica e

1. A autora agradece a Rafael Lopes Souza, graduando de Relações Públicas e bolsista PIBIC da Univali pela coleta de dados e à Maria Helena Freitas pela parceria nas discussões bibliométricas.

2. PERSSON, O. The intellectual base and research front of JASIS 1986-1990. (Base de dados de intelectuais e pesquisa do Jornal da Sociedade Americana de Ciência da Informação 1986-1990) Journal of the American Society for Information Science (JASIS), v. 45, n. 1, 1994. p. 31-38. 
tecnológica, aos formuladores de políticas científicas em geral e aos gestores de centros de pesquisa e de universidades. Aos bibliotecários interessa porque fornece subsídios para adequar coleções às necessidades dos usuários. Explica uso de literaturas específicas, padrões de uso e padrões de produção científica.

Educomunicação ou a comunicação nos espaços educativos ou ainda comunicação/educação é uma recente área acadêmica que está nascendo como conseqüência da revolução tecnológica. Educadores terão que, a partir de agora, dominar não apenas os conteúdos das suas disciplinas mas também os novos meios de comunicá-los. A expressão "educomunicação" foi cunhada recentemente por Kaplun $^{3}$ e tem como um dos principais objetivos a produção e o desenvolvimento de ecossistemas comunicativos.

Por isso a educomunicação é um espaço epistemológico de intersecção entre a educação e a comunicação social, abrangendo áreas como a educação para a comunicação (estudos de audiência, teorias da recepção) e, mais recentemente, a mediação das tecnologias na educação. Isso porque o computador (lêem-se redes telemáticas) veio recolocar novamente os meios de ensino como tema de pesquisa.

Alguns autores acreditam que o computador conseguiu recolocar a questão porque nem o rádio nem a televisão tinham tido a penetração esperada na educação, devido aos seus aspectos excessivamente lúdicos e comerciais ${ }^{4}$. $O$ fato é que o com- putador trouxe junto novamente o rádio e a televisão para o centro da cena naquilo que vem sendo chamado de convergência digital. Agora, mais do que nunca, voltados para ações formais e não formais de educação, como nas "emissoras de rádio e TVs educativas, editoras e centros de material didático, nas instituições que administram programas de educação a distância e outras"`.

\section{PERGUNTAS DA PESQUISA}

1) Quais os autores nacionais e internacionais que constituem a Frente de Pesquisa na área da Educomunicação na revista Comunicação \& Educação, editada pela ECA/USP no período 1994-2001 ?

2) Há concentração de autores para que possamos chamar de Frente de Pesquisa; esses seriam os autores mais produtivos $\mathrm{e}$ influentes? Em outras palavras, a área já possui maturidade teórica para possibilitar uma concentração de autores?

3) Há concentração de autores oriundos de uma das áreas, Comunicação ou Educação?

4) Seriam clássicos os autores mais influentes na área ou uma massa de jovens autores se enuncia, ampliando o colégio invisível com a proliferação dos congressos $\mathrm{e}$ dos cursos de pós-graduação no Brasil?

5) Qual o impacto de autores internacionais nos trabalhos brasileiros?

As áreas de intersecção epistemológica sofrem por parte dos que a praticam e por

3. SOARES, Ismar de Oliveira. Educomunicação: ou a comunicação nos espaços educativos. In: BICUDO, M. A. V. Formação do educador e avaliação educacional. v,4. São Paulo: UNESP, 1999, p.105-118.

4. SOARES, Ismar de Oliveira. Educomunicação: ... op. cit.

5. SOARES, Ismar de Oliveira. Educomunicação: ... op. cit. p. 113. 
parte dos que a avaliam toda sorte de dificuldades classificatórias. Seja nas tabelas de classificação das agências de fomento (as famosas tabelas de Capes e CNPq) seja nas tabelas tradicionais de classificação decimal dos bibliotecários. O fato é que as novas áreas não se encaixam. Por uma razão muito simples: elas não existiam antes. São de fato áreas novas. O discurso da interdisciplinaridade lançado na década de 60 por inspiração francesa de Gusdorf ${ }^{6}$ ganhou abrangência mundial e consolidou-se hoje como senso comum nas universidades de todo o mundo. Mas o fato é que a interdisciplinaridade não precisa ser pensada apenas como dadivosa cooperação entre as áreas, inclusive porque ela representa também a ruptura entre as áreas para a constituição de novas áreas. Assim, os espaços interdisciplinares são espaços necessariamente contraditórios (porque negam os espaços originários anteriores) e representam, na sua fase inicial, indagações gerais à espera de aprofundamentos e contornos até que se tornem espaços disciplinares estabelecidos. Aprofundamentos vão se dando na medida em que haja investimento através da formação de pesquisadores e seus programas de doutorado, seja investimento na produção editorial de revistas científicas do novo campo, ou através da difusão de programas de ensino graduado. Processos demorados porque envolvem formação de recursos humanos e de produção de conhecimento, processos mutuamente determinantes.
Mapear a Educomunicação, área nova no cenário acadêmico brasileiro, em termos de recursos humanos (autores) e respectiva produção científica, dando visibilidade ao campo científico, ajuda a aliviar o parto da nova área no mapa das ciências sociais aplicadas.

A análise de citações como parte dos estudos bibliométricos na literatura da Educomunicação complementa, quiçá, os trabalhos dos que vêm se dedicando à cartografia da área.

\section{BIBLIOMETRIA: DISTRIBUIÇÃO BÁSICA}

A Bibliometria comporta três leis básicas:

"1. A Lei de Bradford, que descreve a distribuição da literatura periódica numa área específica; 2 . a lei de Lotka, que descreve a produtividade dos autores; e 3 . a lei de Zipf, que descreve a freqüência no uso de palavras num determinado texto. A este grupo básico de leis agregam-se, posteriormente, outros estudos que, apesar de ainda não serem considerados leis, configuram o corpo das preocupações dos cientistas da informação, a saber: a) a Lei de Goffman, que descreve a difusão da comunicação escrita como um processo epidêmico; b) a Frente de Pesquisa ou Elitismo, que descreve de que modo uma

6. Ver sobre o tema: VEIGE NETO. Alfredo. A ordem das disciplinas. Porto Alegre: UFRGS, 1996. (Apresentação da tese de doutoramento) Disponibilizado em: <http://orion.ufrgs.br/faced/alfredo/defesall.htm.> 
seleta pequena parte da literatura mais recente está relacionada remota e aleatoriamente a uma parte maior da literatura mais antiga; e c) a Obsolescência/Vida média/ Idade da literatura que descreve a queda da validade ou utilidade de informações no decorrer do tempo"?

Como esclarece Urbizagástegui Alvarado ${ }^{8}$, a Biologia também desenvolve uma subárea chamada biometria; a psicologia desenvolve a psicometria; a economia, econometria e a sociologia notabilizou-se pela sociometria de Moreno ${ }^{9}$, que deu lugar a tantos estudos na década de 60 . Com efeito, no clássico livro Fundamentos de la Sociometria, Moreno já intuía a utilidade das técnicas sociométricas para o estudo das "citas" (as citações).

A distribuição da informação entre as revistas técnico-científicas é de tal ordem que, para encontrarmos o mesmo, número de artigos relevantes, é preciso consultar um periódico da literatura-núcleo, cinco textos na literatura de domínio conexo e 25 das áreas mais periféricas, conforme esclarece Le Coadic ${ }^{10}$. É o mesmo que dizer que, lendo apenas os periódicos da literatura-núcleo, já se terão encontrado quase $40 \%$ dos artigos relevantes.

Há formas mais matematizadas de dizer o mesmo. Com efeito, a Ciência da Informação explorou todas essas formas: distribuições hiperbólicas são distribuições em que o produto de potências fixas das variáveis é constante: $\mathrm{F}(\mathrm{x}) \cdot \mathrm{x}$ elevado a $\mathrm{n}=$ constante.

Diz-se, portanto, que as relações informacionais ou são de natureza hiperbólica ou são de natureza logarítmica. A uma causa (insumo) que cresce de modo geométrico, corresponde um efeito (produto) que cresce de modo aritmético. São as mesmas leis do reflexo encontradas na psicologia comportamental. Ou no consumo de drogas: chega a um ponto em que é necessário muito mais insumo para causar o mesmo efeito. Regularidades conhecidas como lei dos rendimentos decrescentes.

Em exemplos, Price ${ }^{11}$ encontrou no evangelho de São Matheus ("a todo aquele que tem será dado em abundância, mas daquele que não tem, até o que tem será tirado") as premissas básicas dos processos cumulativos da informação: o rico fica mais rico; o pobre empobrece ainda mais.

Uma forma sistemática de enunciar o evangelho está em Le Coadic ${ }^{12}$ :

- "um artigo que já foi citado numerosas vezes será citado mais freqüentemente do que um artigo que só recebeu poucas citações;

- uma revista que é freqüentemente consultada será mais regularmente consultada do que as que são menos consultadas;

- um autor que já publicou muitos artigos publicará outros mais facilmente do que quem não publicou tanto;

7. AlVARADO, Urbizagástegui. A Bibliometria no Brasil. Ci.Inf. Brasilia. v. 13, n. 2, 1984. p. 91.

8. ALVARADO. Urbizagástegui. A Bibliometria ... op. cit. p. 91.

9. MORENO. J. L. Fundamentos de la sociometria. 2. Ed. Buenos Aires: Paidós, 1972.

10. LE COADIC, Yves-François. A ciência da Informação. Brasília: Briquet de Lemos/Livros, 1996.

11. PRICE, D.J.D. Little Science, Big Science. (Pequena ciência, grande ciência) New York: Columbia Univ. Press, 1963. Veja também do mesmo autor os não menos famosos artigos Network of scientific papers. Science, 1965. p. 149-510 e A general theory of bibliometrics and other cumulative advantage processes. JASIS, 27. 1973. p. 120-134.

12. Se a Bibliometria nasceu na Inglaterra com Bradford, que realizou o primeiro estudo na década de 40 , tendo Brookes sido o inglês que na década de 60 mostrou Bradford ao mundo, quase que inaugurando a Bibliometria como área de estudos, e encontrando nos EUA um terreno forte de crescimento por conta do pragmatismo americano, a produção francesa na área vem se revelando notável. Além deste livrinho didático, publicado em português, veja também o endereço do sítio de Marseilles: <http://crrm.univ-mrs.fr/vl/metricts.html> 
- há palavras que fazem parte da linguagem comum, enquanto outras são raramente utilizadas;

- o milionário enriquece mais rápido do que o pobre" 13 .

\section{CÉU DE CINCO ESTRELAS}

Hoje já é difícil enumerar as "estrelas bibliométricas" devido, quiçá, ao mesmo fenômeno que a Bibliometria estuda, qual seja, o próprio crescimento da ciência. Uma rápida olhada nas Conferências Internacionais de Bibliometria $^{14}$ revela uma proliferação de autores do mundo todo, estudando os fenômenos bibliométricos. Mas nas décadas iniciais de 60 e 70 (um pouco de 80 ) surgiram nomes que se notabilizaram pela originalidade das descobertas que trouxeram.

Assim, além do já citado Derek de Sola Price, cujos livros foram traduzidos para o português - $O$ desenvolvimento da Ciência e A ciência desde a Babilônia - não se pode deixar de mencionar alguns autores em suas especialidades bibliométricas.

Por exemplo, o nome de Maurice Line estará para sempre ligado à obsolescência da literatura no texto de 1974 Obsolescence and changes in the use of literature with time ${ }^{15}$. Small é outro autor que desenvolveu os estudos de citação em Co-citation in the scientific literature: a measure of the relationship between two documents ${ }^{16}$. Textos que se tornaram clássicos na literatura internacional.

Análise de Citações é um dos temas da Bibliometria mais populares depois da Lei de Bradford: Estudo de citações da literatura produzida pelos professores do Instituto de Ciências Biológicas da UFMG ${ }^{17}$; Análises bibliométricas da literatura de química no $\mathrm{Brasil}^{18}$; Seleção de periódicos científicos para a área de física. E assim por diante.

Dois comentários:

1) Os temas bibliométricos passaram por certa vulgarização em fins da década de 80 e agora na década de 90 . Vulgarização no sentido de popularização. Já não são tão nobres para serem temas exclusivos de dissertações. Por exemplo, Produção científica ${ }^{19}$ é um livro que reúne 20 pesquisas realizadas em sala de aula por alunos de Mestrado da PUC de Campinas. Nenhuma das pesquisas se refere às leis

13. LE COADIC. Yves-François. A ciência da Informação. Brasília: Briquet de Lemos/Livros, 1996. p. 78.

14. Consulte os links bibliométricos na Internet: $\leq h t t p: / / w w w$.uni-bielefeld.de/iwt/mw/bibliometrics $>$ para ver a proliferação dos autores nesta década de 90. FREITAS, M. H. Oito anos de transinformação. Transinformação. Campinas: Universidade Católica. v. 9, n. 3, 1997. Disponibilizado em: <http://www.puccamp.br/ biblio/transinformacao/old/vol9n3/ su93.html>

15. LINE, M. Obsolescence and changes in the use of literature with time. (Obsolescência e mudança no tempo de uso da literatura.) J. of Documentation, n. 30, 1974. p. 283-359.

16. SMALL, H. Co-citation in the scientific literature: a measure of the relationship between two documents. (Cocitação na literatura científica: uma medida de conexão entre dois documentos) Journal of the American Society of Information Science, n. 24, 1973, p. 265-269.

17. CARVALHO, M. L. Borges de. Estudo de citações da literatura produzida pelos professores do Instituto de Ciências Biológicas da UFMG. Ciência da Informação. Rio de Janeiro, v. 5, n. 1/2, 1976. p. 27-42.

18. CARVALHO. Maria Martha de. Análises bibliométricas da literatura de química no Brasil. Ciência da Informação. Rio de Janeiro, v. 4, n. 2, 1975. p. 119-141.

19. WITTER, Geraldina Porto (org.) Produção científica. Campinas: Átomo, 1997. 
bibliométricas stricto sensu. Não se usa a expressão "bibliometria" em nenhuma delas. Nem se está atrás de saber se tais distribuições são do tipo bibliométricas. São uma espécie de versão da Bibliometria. São análises quantitativas da produção científica dos autores.

2) Diz-se que, no Brasil, a área passou por um recrudescimento... Houve muitas críticas à excessiva matematização exigida na Bibliometria. Mas o fato é que a área renasce em outras tematizações. Os trabalhos mais recentes na década de 90 são assinados por pesquisadores de fora da área de Biblioteconomia e Ciência da Informação, sejam cientistas sociais, sejam das áreas duras ou biológicas.

Parece haver nos últimos anos um movimento de desterritorialização da Ciência da Informação. Cientistas das várias áreas do conhecimento estão estudando suas literaturas específicas. Assim é que $O$ perfil da ciência brasile $i$ $r a^{20}$ é um estudo de dois bioquímicos, desenvolvido dentro de uma área de pesquisa da bioquímica da USP, chamada Educação, difusão e gestão em Biociencias; o programa de doutoramento de Psicologia da PUC de Campinas também tem uma linha de pesquisa intitulada Psicologia: ciência e profissão, onde são desenvolvidos estudos de produção científica em Psicologia. Vários outros exemplos evidenciam um certo deslocamento da área, o que fez parecer aos cientistas de informação stricto sensu que a área estava em franco descenso.

Ao contrário, há estrelas nascendo no firmamento. Mormente agora com as novas tecnologias de comunicação e informação, a área ganha novo fôlego na chamada Informetria ou Webiometria ${ }^{21}$. A doença da vaca louca, por exemplo, foi estudada por processos bibliométricos logo após a eclosão da crise na Europa. E com uma novidade: os processos bibliométricos foram aplicados aos grupos de discussão europeus da Internet sobre a "mad cow disease" 22 (doença da vaca louca).

\section{METODOLOGIA}

Foram contabilizadas todas as 1.170 citações (647 nacionais e 523 internacionais) publicadas em 28 artigos internacionais e 91 artigos nacionais dos 21 fascículos do periódico Comunicação \& Educação $o^{23}$, de 1994 a 2001. Quando o mesmo autor citante cita várias vezes um mesmo trabalho, este é contado apenas uma vez; quando as citações referemse a trabalhos distintos do mesmo autor, este é contado tantas vezes quantas forem os seus trabalhos distintos. Considerou-se o autor citado, título do trabalho e as fontes bibliográficas nas quais os trabalhos citados foram publicados. Autocitações foram desprezadas para a análise pois elas não representam o impacto de um trabalho sobre o outro.

20. MEIS, Leopoldo, LETA, Jacqueline. O perfil da ciência brasileira. Rio de Janeiro: UFRJ, 1996. 103p.

21. WORMELL, Irene. Online searching is like gold-washing. (Pesquisa online é como garimpar.) Paper presented at the Online Information Scandinavia '98. Exhibition and Conference. May 12-14, 1998. Stockholm International Fairs. 22. BAR - ILAN, Judit The "mad cow disease", usenet newsgroups and bibliometric laws. (A doença da vaca louca, grupos de discussão e normas bibliométricas.) Scientometrics, v. 39 n.1, 1997.p. :29-55.

23. O estudo analisa a partir da bibliometria a revista Comunicação \& Educação. São Paulo: CCA-ECA-USP/Moderna-Segmento. 1994-2001.21v. 


\section{RESULTADOS}

Tab. 1: Freqüência de citações por autoria nacional no periódico Comunicação \& Educação Período 1994-2001

\begin{tabular}{|c|c|c|c|c|c|}
\hline & \multirow{2}{*}{$\begin{array}{r}\text { Autor } \\
\text { BACCEGAMA }\end{array}$} & \multirow{2}{*}{$\frac{\text { Freq. Citações }}{11}$} & \multirow{2}{*}{$\frac{\% \text { Citação }}{1,70}$} & \multirow{2}{*}{$\frac{\Sigma \text { de } \% \text { de Cit. }}{1,70}$} \\
\hline \multicolumn{2}{|c|}{\begin{tabular}{|l|l}
$\Sigma^{* 24}$ de $\%$ de Autor \\
1 & 0,22
\end{tabular}} & & & & \\
\hline 2 & 0.44 & LÉVYP & 9 & 1,39 & 3,09 \\
\hline 3 & 0,66 & $\mathrm{ECOU}$ & 8 & 1,24 & 4,33 \\
\hline 4 & 0,88 & BAUDRILLARD J & 6 & 0,93 & 5,26 \\
\hline 5 & 1,10 & MARCONDES FILHO C & 6 & 0,93 & 6,18 \\
\hline 6 & 1,32 & ADORNO T HORKHEIMER M & 5 & 0.77 & 6,96 \\
\hline 7 & 1,54 & CERTEAU M & 5 & 0,77 & 7,73 \\
\hline 8 & 1,76 & DELEUZE G & 5 & 0,77 & 8,50 \\
\hline 9 & 1,98 & GIROUX H & 5 & 0,77 & 9,27 \\
\hline 10 & 2,20 & HOBSBAWNE & 5 & 0,77 & 10,05 \\
\hline 11 & 2,42 & MARTÍN-BARBERO J & 5 & 0,77 & 10,82 \\
\hline 12 & 2,64 & MORIN E & 5 & 0,77 & 11,59 \\
\hline 13 & 2,86 & VYGOTSKYLS & 5 & 0,77 & 12,36 \\
\hline 14 & 3,08 & BABIN P KOULOUMDJIAN M & 4 & 0.62 & 12,98 \\
\hline 15 & 3,30 & CANCLININ & 4 & 0,62 & 13,60 \\
\hline 16 & 3,52 & DEMO P & 4 & 0,62 & 14,22 \\
\hline 17 & 3,74 & FREIRE $P$ & 4 & 0,62 & 14.84 \\
\hline 18 & 3,96 & GADOTTI M & 4 & 0.62 & 15,46 \\
\hline 19 & 4,18 & GONÇALVES C W P & 4 & 0,62 & 16,07 \\
\hline 20 & 4,40 & MATTELART A MATTELART M & 4 & 0,62 & 16,69 \\
\hline 21 & 4,62 & NETO JP & 4 & 0,62 & 17,31 \\
\hline 22 & 4.84 & OROZCO G G & 4 & 0,62 & 17,93 \\
\hline 23 & 5,06 & SOARES IO & 4 & 0,62 & 18,55 \\
\hline 24 & 5.28 & ALTHUSSER L & 3 & 0,46 & 19.01 \\
\hline 25 & 5.50 & APPLE M & 3 & 0,46 & 19,47 \\
\hline 26 & 5,72 & BARBOSA A M & 3 & 0,46 & 19.94 \\
\hline 27 & 5,94 & BOURDIEU P & 3 & 0,46 & 20,40 \\
\hline 28 & 6.16 & BUARQUE C & 3 & 0.46 & 20,87 \\
\hline 29 & 6,38 & CITELLIA O & 3 & 0,46 & 21,33 \\
\hline 30 & 6,60 & CUNHA M & 3 & 0,46 & 21,79 \\
\hline 31 & 6,82 & EISNER W & 3 & 0,46 & 22,26 \\
\hline 32 & 7,04 & HABERMAS J & 3 & 0,46 & 22,72 \\
\hline 33 & 7,26 & JACQUINOT G & 3 & 0,46 & 23,18 \\
\hline 34 & 7,48 & MACHADOA & 3 & 0,46 & 23,65 \\
\hline 35 & 7,70 & MATTELART A & 3 & 0,46 & 24,11 \\
\hline 36 & 7.92 & NOSELLAP & 3 & 0,46 & 24,57 \\
\hline 37 & 8,14 & RAMOS JMO & 3 & 0,46 & 25,04 \\
\hline 38 & 8,36 & RIBEIRO S C & 3 & 0,46 & 25,50 \\
\hline 39 & 8,58 & SABOYAA & 3 & 0,46 & 25,97 \\
\hline 40 & 8.80 & SANTOS M & 3 & 0,46 & 26,43 \\
\hline 41 & 9,02 & SAVIANID & 3 & 0,46 & 26,89 \\
\hline 42 & 9,24 & ALMEIDA J & 2 & 0,31 & 27,20 \\
\hline 66 & 14,52 & KAPLUNM & 2 & 0,31 & 34,62 \\
\hline 67 & 14,74 & KENSKIV & 2 & 0,31 & 34,93 \\
\hline (...) & & 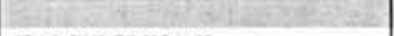 & & & \\
\hline 103 & 22,66 & ZAMPRONHA E. & 2 & 0,31 & 46,06 \\
\hline & 77,21 & 349AUTORES & 1 & 0,15 & 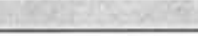 \\
\hline
\end{tabular}




\section{DISCUSSÃO DOS RESULTADOS}

Analisando o grupo de autores com até três citações, percebe-se, pela comparação das colunas dos somatórios $(\Sigma$ de $\%$ de Autor e $\Sigma$ de \% de Cit.), que esse grupo concentra grande parte da producão científica: $22,66 \%$ dos autores citados em Comunicação \& Educação respondem por $46,06 \%$ da produção científica.

É muito diferente, porém, a aproximação desses autores ao campo. Os autores nacionais mais diretamente ligados ao campo da Educomunicação são: Baccega, Soares e Citelli, oriundos da Comunicação. Os educadores presentes neste grupo contribuem indiretamente para a constituição do campo; salvo melhor juízo e com exceção de Giroux, nenhum deles trabalha na intercessão epistemológica da educomunicação. São eles: Demo, Freire, Gadotti, Apple, Nosella e Saviani. Com as devidas especificidades das contribuições, todos esses educadores trabalham com fundamentos da educação na busca de uma pedagogia democrática e popular. O nome de Vygotsky neste grupo demonstra as preocupações do campo com a psicologia da aprendizagem nos novos meios; esse conjunto de autores oriundos da Educação ou da Psicologia da Aprendizagem demonstra a abertura do campo para uma boa interdisciplinaridade. O segundo grupo de autores com até duas citações concentra um conjunto de educadores que, outra vez, salvo melhor juízo, estão dando suporte teórico às questões da formação do professor mas não diretamente na formação do professor, dos novos meios de co- municação. São eles: André, Gatti, Mello, Novoa, Kenski, Ribeiro e Cunha. Apenas Kenski neste grupo liga-se mais diretamente ao campo da Educomunicação e Cunha acomoda-se melhor no primeiro grupo dos Fundamentos da Educação.

Com relação aos autores oriundos da Comunicação e que estão na frente de pesquisa do campo da Educomunicação a liderança de Baccega, Soares e Citelli pode ser considerada constitutiva do campo.

Baccega coloca de forma original a "edição" do mundo já no primeiro fascículo da revista. E se tal, é preciso conhecer o processo de produção deste mundo enquanto uma nova edição. Ou uma edição em "permanente construção". Para tal, chama a atenção dos dois pólos desta construção: os meios de comunicação e os receptores dos meios de comunicação. Se há certa onipresença dos meios ('não dá mais pra segurar', diria o querido Gonzaquinha”...) os receptores também estão em todo lugar. A recepção implica também uma construção.

O segundo fascículo da revista vem marcado por essa dialética entendida, no quarto fascículo, como "mediações" que mais tarde serão qualificadas como mediações da linguagem (fascículo 15). E aqui reside o fulcro de interesse da autora: dois dos seus livros ${ }^{25}$ citados referem-se à lin- 
guagem e à complexa noção de discurso, quiçá um aprofundamento (lingüístico) da noção de edição. $\mathrm{O}$ fato de Baccega ser a editora da revista coloca-a na posição de apresentadora com 18 aparições assinadas, o que dá mais visibilidade ao seu nome. Cinco de seus editoriais/ apresentações têm, contudo, a força argumentativa do artigo científico uma vez que são citados como tal. É o caso de Comunicação/Educação e Transdisciplinaridade: os caminhos da linguagem; Recepção: nova perspectiva nos estudos de comunicação, Comunicação e cultura, Conhecimento, informação... e, Do mundo editado à edição do mundo ${ }^{26}$; esse último com impacto também para a própria autora que o retoma em várias edições como na apresentação do $21^{\circ}$ fascículo.

Pierre Levy, o autor mais citado no campo da Educomunicação, tem sido apontado como o filósofo do ciberespaço. Especialmente no primeiro livro $A s$ tecnologias da inteligência texto que recebeu a maioria das citações de Comunicação \& Educação. É neste livro que o autor coloca o hipertexto no centro da teoria da comunicação, como metáfora da comunicação, passando a falar em "teoria hipertextual da comunicação". Tal inovação não passou despercebida pelos autores brasileiros de Comunicação \& Educação que passaram a revisitar seus conceitos, como por exemplo o conceito de "ecologia cognitiva", central na obra de Levy como plataforma da nova forma de conhecer.

Diferentemente dos autores da comunicação que tematizam os planos da emissão e/ou recepção de mensagens (nas formas clássicas de mensagens e canais ou nas formas mais modernas das teorias da recepção), Levy vai falar na rede de significações através do hipertexto, suportada por uma plataforma cognitiva de mensagens, meios, recursos informacionais e jogos de linguagem que configuram a nova forma de conhecer. É portanto uma inovação em relação às teorizações realizadas no campo da comunicação. E por isso, talvez o autor tenha recebido tanta atenção dos autores de Comunicação \& Educação.

É importante destacar a contribuição de mais dois autores constituintes da área: Martín-Barbero, o espanhol colombiano, na sua compreensão que vai dos meios às mediações (esse é o título do seu livro mais citado pelos educomunicadores brasileiros), é a referência latino-americana mais importante do campo (entre os internacionais e somadas as co-autorias, Martín-Barbero se coloca como o autor 'latino-americano' mais citado entre os autores internacionais que escrevem em Comunicação \& Educação). Uma espécie de contraponto ao 'funcionalismo' de Pierre Levy. Martín-Barbero enriquece a teoria da recepção com o conceito de mediação. Sua síntese faz parte das sínteses da década de 80 que vieram relativizar o estruturalismo de uma escola de Frankfurt, por exemplo. Da mesma forma que as leituras de Antônio Gramsci foram importantes, no Brasil da mesma época, para relativizar o estruturalismo althusseriano na compreensão da escola como aparelho ideoló- 
gico do Estado, Martín-Barbero foi a Gramsci para relativizar o estruturalismo da Escola de Frankfurt na compreensão da indústria cultural como campo de mediações e lugar de contradições e de produção também de uma nova ordem cultural.

Babin escreve sobre as novas formas de compreender no sentido de apontar as novidades das linguagens audiovisuais. Sua contribuição é bem mais simples do que a de Levy ou Martín Barbero, aproximando-se mais de nosso senso comum em termos de apontar as cores e formas e sentimentos das linguagens audiovisuais. Babin relata suas experiências na produção de linguagens audiovisuais, alertando-nos de suas especificidades: emoção, cores, formas, movimentos e ritmos. Dizendo-nos que eis aí uma nova cultura; é preciso entendê-la e avaliá-la com outros critérios, diferentes da cultura escrita e reflexiva. Posição bastante diferenciada da de Levy que, ao falar da cultura informática como uma tecnologia da inteligência, não está de forma alguma descomplexificando as formas de conhecer. Ao passo que Babin desce direto do complexo ao simples (da escrita ao som e imagem), pontuando o ritmo e demais possibilidades das linguagens audiovisuais. Ambas as interpretações são importantes no campo da Educomunicação.

Os autores clássicos que estão dando suporte teórico à nova área são: Eco, Baudrillard, Adorno, Certeau, Deleuze, Hobsbawn, Mattelart, Althusser, MartínBarbero, Vygotsky, Bourdieu, Habermas, Benjamin, Gardner, Ianni, Mafessoli,
Marx, Engels, McLuhan, Morin, Pêcheux, Toffler e Williams. Esses autores são oriundos de diversas áreas das Ciências Sociais em várias temporalidades; são oriundos da Comunicação, Filosofia, História, Psicologia da Aprendizagem, Sociologia, Lingüística. São analistas da cultura do seu tempo, por assim dizer, e por isso constituem-se em embasamento para vários campos em formação. Mas é inegável que a presença de alguns deles remete às Teorias da Comunicação, como por exemplo Eco, McLuhan ou Mattelart, este último em História das teorias da comunicação ${ }^{27}$.

Desnecessário dizer que as centenas de autores que foram citados apenas uma vez também estão contribuindo para a formação do campo. É possível que parte deles venha a receber mais citações nos próximos anos. A formação de um campo de estudos é lenta, pois a produção do conhecimento envolve o ritual de transmissão através de cursos e a produção do novo através de pesquisas, essa última etapa envolvendo o julgamento dos pares em bancas examinadoras. Ambos os processos, ensino e pesquisa, estão ancorados em processos de comunicação científica e seu ethos peculiar: teses, periódicos científicos, comitês, bancas examinadoras, congressos, citações e normas bibliográficas e conselhos editoriais. É possível que muitos autores citados apenas uma vez sejam autores inspiradores de novas práticas para outros profissionais, os quais não se tornarão autores e por isso não saberemos o impacto dessa inspiração.

Vejamos como citam os autores internacionais que escrevem em Comunicação \& Educação:

27. MATTELART, Armand e Michele. História das Teorias de Comunicação. 3. ed. São Paulo: Loyola, 2000. 
Tabela 2: Freqüência de citações por autoria internacional no periódico Comunicação \& Educação

Período 1994-2001

\begin{tabular}{|c|c|c|c|c|c|}
\hline & $\Sigma$ de $\%$ de Autor & autor & Freq. Citaçōes & \% Citação & $\Sigma$ de $\%$ de Cit. \\
\hline 1 & 0,30 & FISKE J & 6 & 1,14 & 1,14 \\
\hline 2 & 0.60 & MARTÍN-BARBERO J & 6 & 1,14 & 2,27 \\
\hline 3 & 0,90 & MATTELART A & 6 & 1,14 & 3,41 \\
\hline 4 & 1,20 & TURNER V & 6 & 1,14 & 4,55 \\
\hline 5 & 1,50 & VYGOTSKYLS & 6 & 1,14 & 5,68 \\
\hline 6 & 1,80 & WHITE R & 6 & 1,14 & 6,82 \\
\hline 7 & 2,10 & KAPLÚN M & 5 & 0,95 & 7,77 \\
\hline 8 & 2,40 & LINVINGSTONES & 5 & 0,95 & 8,71 \\
\hline 9 & 2,70 & SILVERSTONE R & 5 & 0,95 & 9,66 \\
\hline 10 & 3,00 & APPLE M & 4 & 0.76 & 10,42 \\
\hline 11 & 3,30 & FREIRE P & 4 & 0,76 & 11,17 \\
\hline 12 & 3,60 & GONZALEZ J & 4 & 0,76 & 11,93 \\
\hline 13 & 3,90 & HALLS & 4 & 0,76 & 12,69 \\
\hline 14 & 4,20 & LECHNER N & 4 & 0,76 & 13,45 \\
\hline 15 & 4,50 & MARQUES DE MELLO J & 4 & 0,76 & 14,20 \\
\hline 16 & 4,80 & SCHMUCLER H & 4 & 0.76 & 14,96 \\
\hline 17 & 5,10 & VIRÍLIOP & 4 & 0,76 & 15,72 \\
\hline 18 & 5,40 & WILLIAMS R & 4 & 0.76 & 16,48 \\
\hline 19 & 5,70 & ALFARO R M & 3 & 0,57 & 17,05 \\
\hline 20 & 6,00 & BARTHES R & 3 & 0,57 & 17,61 \\
\hline 21 & 6,30 & BATES A & 3 & 0,57 & 18,18 \\
\hline 22 & 6.60 & BAUDRILLARD J & 3 & 0,57 & 18,75 \\
\hline 23 & 6,90 & BROWN ME & 3 & 0,57 & 19,32 \\
\hline 24 & 7,20 & CAREY J & 3 & 0.57 & 19,89 \\
\hline 25 & 7,50 & CORONA S & s betite & 0,57 & 20,45 \\
\hline 26 & 7,80 & $\mathrm{ECOU}$ & 3 & 0,57 & 21,02 \\
\hline 27 & 8,10 & FADULA & 3 & 0,57 & 21,59 \\
\hline 28 & 8,40 & FREINET C & 3 & 0,57 & 22,16 \\
\hline 29 & 8,70 & FUENZALIDA V H M & 3 & 0,57 & 22,73 \\
\hline 30 & 9,00 & HOBSON D & 3 & 0,57 & 23,30 \\
\hline 31 & 9,30 & HOLMBERG B & 3 & 0.57 & 23,86 \\
\hline 32 & 9,60 & LIEBES T KATZ E & 3 & 0,57 & 24,43 \\
\hline 33 & 9,90 & MAFFESOLIM & 3 & 0,57 & 25,00 \\
\hline 34 & 10,20 & MARTÍN-BARBERO J M S & 3 & 0.57 & 25.57 \\
\hline 35 & 10,50 & MCLUHANM & 3 & 0.57 & 26,14 \\
\hline 36 & 10,80 & MORLEY D & 3 & 0.57 & 26.70 \\
\hline 37 & 11,10 & SOARESIO & 3 & 0,57 & 27,27 \\
\hline 38 & 11,40 & SODRÉ M & 3 & 0.57 & 27,84 \\
\hline 39 & 11,70 & WOLFM & 3 & 0.57 & 28,41 \\
\hline 40 & 12,00 & ADRIANZÉNE & 2 & 0,38 & 28,79 \\
\hline 41 & 12,30 & AGUIRRE J & 2 & 0,38 & 29,17 \\
\hline 42 & 12,60 & ALFONZOA & 2 & 0,38 & 29.55 \\
\hline \multicolumn{6}{|c|}{$(\ldots)$} \\
\hline 120 & 36.00 & WARTELLAE & 2 & 0,38 & 59,09 \\
\hline \multirow{2}{*}{121} & 136,30 & WINNER L & 2 & 0,38 & 59,47 \\
\hline & 63,77 & 213 AUTORES & 1 & 0.19 & \\
\hline
\end{tabular}


A primeira constatação que surpreende na comparação entre os dois conjuntos de literatura é que Pierre Levy parece ser um autor importante para os educomunicadores brasileiros mas não para os autores latino-americanos que escrevem em Comunicação \& Educação. Levy não parece sequer fazer parte das preocupações latino-americanas que não devotam a ele nenhuma citação.

Considerando-se até três citações, os autores comuns nos dois conjuntos são: Martín-Barbero, Mattelart, Vygotsky, Apple, Freire, Baudrillard, Eco e Soares. Desses, Vygotsky, Apple e Freire despontam como a abertura da área para os aprofundamentos pedagógicos, faltando a visibilidade disto expressar-se em citações a autores nacionais (jovens) formuladores do novo campo (possivelmente muitos autores que não foram citados ou receberam apenas uma citação estão entre os novos formuladores; os que receberam duas citações podem ser identificados nas tabelas; compõem, possivelmente, o conjunto dos novos formuladores do campo).

Dos autores brasileiros citados pelos colegas internacionais, apenas Soares e Baccega estão na área de intercessão entre a Comunicação e a Educação; os demais estão mais voltados para a área de Comunicação (Marques de Mello, Fadul e Sodré).

Aqui também valem os mesmos comentários já apontados para a produção nacional: a área da Educomunicação aguarda maior contribuição das teorias pedagógicas na constituição do campo, neste conjunto particular de literatura citada na revista Comunicação \& Educação.
Os educadores estão sendo solicitados no campo dos Fundamentos da Educação e na área de Formação de Professores, mas nenhum nome novo (exceção feita a Kenski) oriundo da educação pode ser apontado como constitutivo da Educomunicação. É possível que autores não identificados por terem recebido apenas uma citação ou mesmo os que não receberam citação estejam entre os novos formuladores do campo, sendo que seus nomes ainda irão emergir num futuro próximo.

O campo da Educomunicação visita, assim, as Teorias da

Comunicação e da Cultura, os Fundamentos das Teorias Pedagógicas e a Formação de Professores, num ensaio mais do que necessário para fundar a Teoria da Educomunicação

stricto sensu.

Toda a análise realizada até agora referiu-se às seções de Artigos da revista $\mathrm{Co}$ municação \& Educação. O artigo científico tem, dentre as suas especificidades, a referência a outros autores. Há, porém, na revista Comunicação \& Educação uma seção chamada 'Experiência', na qual professores do ensino fundamental e médio relatam suas experiências em sala de aula com os meios de comunicação. Assim, por exemplo, há relatos intitulados: Os meios de comunicação de massa nas aulas de História ou Aulas de culinária para crianças, Exercícios com jornais, Alunos 
de sexta série produzem uma revista, $O$ jornal e as notícias nas aulas de Portugu$\hat{e} s$, e outras experiências que podem estar tendo bastante impacto entre professores e demais educomunicadores, mas não foram objeto de análise nesta pesquisa por não conterem, os relatos de experiência, a obrigatoriedade da citação a outros autores.

\section{Padrão de Citações entre os Autores Nacionais e Internacionais Revista Comunicação \& Educação}

\begin{tabular}{|c|c|c|c|c|c|c|c|c|c|}
\hline \multirow{2}{*}{ Ano } & Publicação & \multicolumn{2}{|c|}{ Artigos } & \multicolumn{2}{c|}{$\begin{array}{c}\text { Art/Pub } \\
\text { c/citações }\end{array}$} & \multicolumn{2}{l|}{ Citações } & \multicolumn{2}{l|}{ Cit/Art } \\
\cline { 2 - 10 } & Nac / Inter & Nac & Inter & Nac & Inter & Nac & Inter & Nac & Inter \\
\hline 1994 & 1 & 2 & 1 & 2 & 1 & 6 & 9 & 3 & 9 \\
1995 & 3 & 16 & 3 & 5 & 1 & 57 & 15 & 4 & 5 \\
1996 & 3 & 14 & 4 & 5 & 1 & 53 & 52 & 4 & 13 \\
1997 & 3 & 11 & 3 & 4 & 1 & 135 & 45 & 12 & 15 \\
1998 & 3 & 12 & 4 & 4 & 1 & 76 & 124 & 6 & 31 \\
1999 & 3 & 15 & 4 & 5 & 1 & 77 & 70 & 5 & 18 \\
2000 & 3 & 12 & 6 & 4 & 2 & 87 & 37 & 7 & 6 \\
2001 & 2 & 9 & 3 & 5 & 2 & 74 & 54 & 8 & 18 \\
Total & 21 & 91 & 28 & & & 565 & 406 & & \\
Média & & & & 4 & 1 & & & 6 & 14 \\
\hline
\end{tabular}

O quadro acima demonstra o padrão de citação dos autores nacionais e internacionais: os autores nacionais citam em média seis trabalhos, enquanto os internacionais citam, em média, quatorze trabalhos. O padrão de citação entre os brasileiros pode ser reflexo da política editorial da Revista e pelo fato de esta Revista pertencer a um curso de pós-graduação lato sensu em Gestão de Processos Comunicacionais, o que faz com que a produção científica seja mais voltada para a atualização profissional, demandando um nível de teorização diferente em relação aos programas stricto sensu como mestrado ou doutorado. A literatura científica é sensível aos arranjos institucionais socioculturais nos quais ela se desenvolve. Por isso a revista científica é chamada de espelho da ciência ${ }^{28}$. 
Resumo: $\mathrm{O}$ artigo tem por objetivo o estudo bibliométrico da revista Comunicação \& Educação, de 1994 a 2001, perfazendo 21 volumes. O estudo bibliométrico é uma área da Ciência da Informação e aponta os autores mais citados num campo científico e de que forma esses autores, provenientes de áreas distintas, contribuem para este campo. A autora faz levantamento dos autores mais citados em artigos nacionais e internacionais da revista, identificando suas área de origem e comentando as contribuiçōes da Comunicação, bem como aponta a falta de referências autorais na área da Educação, na formação do campo da Educomunicação.

Palavras-chave: Educomunicação, comunicação/educação, Bibliometria, Bibliografia, campo científico, comunicação, autores
(Epistemological quotations in the field of educommunication)

Abstract: The article aims at performing a bibliometric study of Comunicação \& Educação, from 1994 to 2001, totaling 21 volumes. Bibliometric studies is an area of Information Science and it brings up the most quoted authors in a scientific field and how such authors, coming from distinct areas, contribute to such field. The author surveys the most quoted authors in the magazine's national and international articles, identifying their areas of origin and commenting the contributions Communications have made. Furthermore, she points to the lack of authorial references in Education, especially in forming the field of Educommunication.

Key words: Educommunication, communication/ education, Bibliometry, Bibliography, scientific field, communications, authors 